Research/Technical Note

\title{
Development of CD-Rom to Appraise Nutritional Knowledge of the Information Technology Professionals
}

\author{
Priya Sharma, M. Usha Rani, K. Uma Maheswari \\ Department of Foods and Nutrition, Post Graduate and Research Centre, ANGRAU, Hyderabad, Andhra Pradesh, India
}

Email address:

sharmapriya0304@gmail.com (P. Sharma)

\section{To cite this article:}

Priya Sharma, M. Usha Rani, K. Uma Maheswari. Development of CD-Rom to Appraise Nutritional Knowledge of the Information Technology Professionals. Journal of Food and Nutrition Sciences. Vol. 4, No. 1, 2016, pp. 7-10. doi: 10.11648/j.jfns.20160401.12

\begin{abstract}
Computer technology provides the opportunity to explore new and creative methods of delivering nutrition education to the professionals in information technology sector. It has the potential to make learning about nutrition more interesting, informative, enjoyable, exciting and effective. This can also helps to reach large population with accurate and consistent nutrition education with greater efficiency and in less time. The purpose of this study was to develop and evaluate the appropriate digital nutrition education material, CD-Rom to appraise the IT professionals on balanced diet, good eating habits \& correct food choices. As part of a community nutrition education program, nutrition education material in the form of CD-Rom was developed keeping in view the updated scientific information. The identified areas for development of CD-Rom included balanced diet, classification of foods based on their functions, nutritional significance of nutrients, therapeutic information, importance of physical exercises and dietary guidelines for Indians. The study demonstrated that nutrition and health related messages incorporated in the digital nutrition education material successfully transmitted to the target group of adults.
\end{abstract}

Keywords: Information Technology Professionals, Nutrition Education, CD-Rom

\section{Introduction}

Physical demands were a typical aspect of daily life. In modern times, many of these demands on the human body are no longer part of daily life due to mechanization of the society, i.e., an increased use of automobiles and decreased opportunities to walk in many modern living areas. Such changes in lifestyle have also reflected the rising prevalence of various chronic diseases like obesity and diabetes especially, among the sedentary population (Gupte et al., 2001). The professionals in the IT sector are at nutrition and health risk. Such professionals in the companies with ample access to energy-rich foods and low physical levels are at increased risk of becoming overweight or obese. Since the sedentary lifestyle is growing fast in the information technology sector, the number of IT professionals suffering from chronic diseases is increasing. Interventions are needed for nutritional health promotion of the target individuals and that can be delivered inexpensively to large segments of the population.

The CD-ROM is a cheap and rapid tool for the distribution of up-to-date knowledge to the population. With due consideration, the digital nutrition education material, CD-Rom to appraise the professionals on importance of balanced diet, good eating habits and correct food choices to lead a healthy life and achieve their targets was developed. A number of studies have been conducted on nutrition interests and health needs in different populations, such as adolescent girls (Kaur et al., 2007), young women (Joshi and Vijayalaxmi, 2009) and many others, but there have been few studies among young adults, who are potential target group for nutrition education.

Nutrition education lessons were given to a group of IT professionals with the purpose of increasing their nutrition knowledge and ultimately changing behavior. Topics that were covered in each lesson were relevant to the IT professionals. This pilot study will form the basis for planning educational interventions not only to improve the nutrition knowledge but also change in the attitudes related to food, nutrition and health issues.

The purpose of this study was to develop digital nutrition education material, CD-Rom for improving the nutritional knowledge levels of the subjects and to appraise the 
professionals on balanced diet, good eating habits \& correct food choices.

\section{Development of Digital Nutrition Education Material}

\subsection{Developing the CD-ROM}

The CD-Rom was developed on the specific areas identified from the information elicited from the study samples on physical activity pattern; food preferences; food consumption and meal pattern and knowledge levels and anthropometry of the professionals keeping their socio-economic profile as the background. The content of the CD-Rom was prepared with the help of Microsoft Office Power Point 2007. Then the final draft of the CD-Rom was made into a flash slide show.

\subsection{Nutrition Education Intervention}

Nutrition education is defined as the process by which beliefs, attitudes, environmental influences and understanding about food lead to practice are scientifically sound, practical and consistent with individual needs and available food resources. The importance of nutrition education as a means for improving the nutrition of the community in developing countries has been increasingly realized during the recent years.

Nutritional education was imparted to the subjects after adjudging their basic nutritional knowledge, through the pre-test data collection with the help of structured schedule. The subjects were informed personally about the nutrition education intervention programme.

The professionals were educated about the specific food and nutrition areas that were identified in the study. The developed education material i.e., CD-ROM was then given to the professionals followed by interactive sessions. The subjects attended these interactive sessions at their respective offices.

A pre-test and post-test were used for this study. After respondents had finished the intervention, a post-test questionnaire was provided to them. The post-test questions were identical to the pretest questions; however, the order of the questions was rearranged.

\subsection{Duration of the Nutrition Education Material}

The professionals of four IT companies were interacted once in fifteen days respectively, for a period of one month. The interactive session took between 45 to 60 minutes.

\subsection{Evaluation of the CD-Rom}

At the end of the whole session, the subjects were also asked to evaluate the CD-Rom by examining the degree of understanding, sufficiency of information, self-explanation and usefulness of pictures to understand the content of the education material.

\section{Results and Discussion}

\subsection{Food and Nutrition Areas Identified for Development of CD-Rom}

Understanding the nutritional knowledge and awareness of the target group will help the researcher to identify the grey areas of nutrition so that the information and issues to be incorporated in developing the appropriate nutrition education material. The content of the nutrition education material should be based on assessed individual/group needs.

Nutritionists should plan the nutrition education intervention based on the needs and socio-cultural background of the target group. Information tailored and designed to the audience needs is more effective than providing general information (Trevena et al., 2006).

In the present study, research was carried out prior to the CD-Rom development to elicit information on physical activity pattern; food preferences; food consumption and meal pattern and knowledge levels and anthropometry of the IT professionals keeping their socio-economic profile as the background.

The average knowledge levels of subjects indicated that the basic aspects of nutrition like balanced diet, functions of food etc and specific issues like consequences of consuming junk foods, excessive intake of fat with no physical activity; food pattern etc requires to be incorporated in the e-learning material i.e., CD-Rom.

Stevens et al. (2003) also conducted a study with a 20-min interactive computer-based intervention using a touch-screen format on healthy women and showed significant decrease in dietary fat and increase in fruit and vegetable consumption.

The identified areas and content under each areas of the CD-Rom are summarized below:

- Balanced diet and classification of foods based on their functions.

- Nutritional significance of macronutrients and micronutrients.

- Therapeutic information on obesity, diabetes mellitus and hypertension.

- Importance of physical exercises and dietary guidelines for Indians.

\subsection{Development of Digital Nutrition Education Material i.e., CD-Rom}

\subsubsection{CD-Rom Outlines and Design}

Table 1. Outlines for developing a CD-Rom.

\begin{tabular}{|c|c|}
\hline Section & Topics \\
\hline \multirow{4}{*}{$\begin{array}{l}\text { Balanced diet and } \\
\text { classification of foods } \\
\text { based on their functions }\end{array}$} & A. Introduction to food and nutrition \\
\hline & B. Balanced diet and its importance \\
\hline & C. Sample meal plan for sedentary adults \\
\hline & D. Classification of foods and their functions \\
\hline \multirow{5}{*}{$\begin{array}{l}\text { Nutritional significance } \\
\text { of macronutrients and } \\
\text { micronutrients }\end{array}$} & A. Various nutrients \\
\hline & B. Their importance in human body \\
\hline & C. Nutrient rich good food sources \\
\hline & D. Food guide pyramid \\
\hline & E. Major nutritional deficiencies \\
\hline
\end{tabular}




\begin{tabular}{ll}
\hline Section & Topics \\
\hline $\begin{array}{l}\text { Therapeutic information } \\
\text { on obesity, diabetes } \\
\text { mellitus and hypertension }\end{array}$ & A. Obesity, diabetes and hypertension \\
& B. Dietary management \\
Amportance of physical & A. Physical activity and its benefits \\
$\begin{array}{l}\text { exercises and dietary } \\
\text { guidelines for Indians }\end{array}$ & $\begin{array}{l}\text { C. Good hygienic practices } \\
\text { D. Dietary guidelines for Indians }\end{array}$ \\
\hline
\end{tabular}

Development of self learning e-material in the form of CD-Rom was decided as it is the best means of imparting nutrition education to literate subjects.

The CD-Rom titled "Know your Food for Healthy living" consisted of 67 slides. The main outlines of the content for developing a CD-Rom were given in Table 1 .

The CD-Rom was developed in an appealing design format. Colorful photographs and transition effects were used to maintain the interest of the professionals during an intervention, for better understanding and usage.

A nutrition education program was developed by Bae Eun Young et al. (2007), also resulted into a major contribution to nutritional health promotion by correcting the eating-out habits of youth.

\subsubsection{Contents of the CD-Rom}

The contents of the CD-Rom were developed by reviewing the manuals and text books available on the food and nutrition information, specifically for Indians.

\subsubsection{Developing the CD-Rom}

The staffs of the department of Foods and Nutrition and research associates were consulted to review the CD-Rom. The draft of the CD-Rom was reviewed for fine tuning its appropriateness of the content, sequence, comprehension and finally its appeal to the users.

\subsubsection{Evaluation of the CD-Rom}

An evaluation of the CD-Rom education material was conducted with 40 IT professionals (29 males and 11 females). Most subjects opined that the information in the CD-Rom was informative $(90 \%)$, self-explanatory $(80 \%)$ and easy to understand (75\%) (Table 2). These results suggested that the CD-Rom developed was easy to understand, informative and provided sample menus which would enable them to practice in their daily life.

Table 2. Evaluation of the CD-Rom $N=40$.

\begin{tabular}{llll}
\hline Variables & & $\mathbf{n}$ & $\mathbf{\%}$ \\
\hline \multirow{4}{*}{ Degree of understanding } & Easy to understand & 30 & 75 \\
& On average & 10 & 25 \\
& Difficult to understand & 0 & 0 \\
Degree of information & Informative & 36 & 90 \\
provided & On average & 4 & 10 \\
& Insufficient & 0 & 0 \\
Self-explanatory & Self-explanatory & 32 & 80 \\
& On average & 8 & 20 \\
& Did not explain & 0 & 0 \\
\hline
\end{tabular}

\begin{tabular}{llll}
\hline Variables & & $\mathbf{n}$ & $\mathbf{\%}$ \\
\hline \multirow{3}{*}{$\begin{array}{l}\text { Pictures to understand } \\
\text { contents }\end{array}$} & Helpful & 35 & 87.5 \\
& On average & 5 & 12.5 \\
& Did not help & 0 & 0 \\
Usefulness of materials in & Useful & 31 & 77.5 \\
daily lives & On average & 9 & 22.5 \\
& Not useful & 0 & 0 \\
\hline
\end{tabular}

\section{Summary and Conclusion}

The major topics in the CD-Rom were introduction to balanced diet, various food groups and their functions; nutrients along with their importance in the body; therapeutic information on obesity, diabetes mellitus and hypertension; and the importance of physical exercises, dietary guidelines, suggested menus for sedentary adults. The characteristics of the education material, CD-Rom are as follows:

1) Simple, specific messages were used for IT professionals.

2) Diverse pictures, different animations in many slides were created and used to enhance understanding, interest and attractiveness.

3) Practical tips were provided for healthy eating and correct food choices. For example, tips on reducing fat and salt, increasing calcium and fiber intake, quitting smoking and drinking were presented.

4) Sample menus and food pictures were presented to help the learner to understand the correct dietary patterns.

The rapid increase in obesity prevalence coupled with the expanding fast food industry has become a great public health concern. The interactive material was found to be nutritionally valuable for the IT professionals as it increased their awareness about healthy dietary habits among them. This can further prevent the vulnerability of young generations to various diseases. The food habits of IT professionals have also become increasingly unhealthy which may lead to high risk of chronic diseases. High intakes of fried and junk food may increase the risk of chronic and other diseases, such as obesity and cardiovascular disease. Changes in food habits and preferences towards healthy food choices may help to minimize the disease for this age group. Consequently, developing appropriate strategies to promote a healthy diet for IT professionals in Hyderabad, Andhra Pradesh should be a concern of the nutritionists.

\section{Future Research Directions}

Future research may encompass a detailed research on knowledge, attitude and practices of the IT professionals to know the parameters leading to health risk and nutrition education to create awareness on correct food choices and healthy eating pattern are required.

\section{Acknowledgment}

This study was supported in part by Indian Council of 
Agricultural Research (ICAR-JRF), New Delhi, India. Contents of this publication do not necessarily reflect the views or policies of the ICAR.

\section{References}

[1] Bae Eun Young, Lee Kyung Hea, Lyu Eun Soon and Her Eun Sil. 2007. Development of the computer-assisted nutrition education program of eating-out guidance for teenagers. Korean Journal of Community Nutrition. 12 (4): 462-476.

[2] Dietary Guidelines for Indians- A Manual. 2010. National Institute of Nutrition, Hyderabad. 1-100.

[3] Gupte, M. D., Ramachandran, V and Mutaktar, R. K. 2001. Epidemiological profile of India: historical and contemporary perspectives. Journal of Bioscience. 26 (S4): 437-464.

[4] Kaur, T. J., Kochar, G. K and Agarwal T. 2007. Impact of Nutrition Education on Nutrient Adequacy of Adolescent Girls. Studies on Home and Community Science. 1 (1): 51-55.

[5] John, S., Parimalam, S. R., Karthiga, S and Chellappa, A. R. 2005. Nutrition and Dietetics. Tamilnadu Textbook Corporation, Chennai. 187-205.

[6] Joshi, N and Vijayalaxmi, K. G. 2009. Nutritional education tool to improve overall dietary attitude and knowledge among young women. Journal of Human Ecology. 25 (3): 187-191.

[7] National Institute of Nutrition, Hyderabad. 2009. A Report of the Expert Group of the Indian Council of Medical Research. Nutrient requirements and Recommended Dietary Allowances for Indians.

[8] Sharma, Priya. 2012. Development and evaluation of $\mathrm{CD}-\mathrm{ROM}$ as a teaching tool for nutrition education of professionals in information technology sector. M. Sc. Thesis. Acharya N. G. Ranga Agricultural University, Hyderabad, India.

[9] Srilakshmi, B. 2009. Dietetics. New Age International Publishers Limited, New Delhi. 173-193.

[10] Srilakshmi, B. 2007. Food Science. New Age International Publishers Limited, New Delhi. 1-5.

[11] Srilakshmi, B. 2012. Nutrition Science. New Age International Publishers Limited, New Delhi.

[12] Stevens, V. J., Glasgow, R. E., Toobert, D. J., Karanja, N and Smith, K. S. 2003. One-year results from a brief, computer-assisted intervention to decrease consumption of fat and increase consumption of fruits and vegetables. Preventive Medicine. 36 (5): 594-600.

[13] Swaminathan, M., 1988. Essentials of Food and Nutrition Volume I and II. The Bangalore printing and Publishing Co. Ltd, Bangalore.

[14] Trevena, L. J., Davey, H. M., Barratt, A., Butow, P and Caldwell, P. 2006. A systematic review on communicating with patients about evidence. The Journal of Evaluation in Clinical Practice. 12 (1): 13-23. 